\title{
〈Research Paper〉
}

\section{Rhodamine 6G Based New Fluorophore Chemosensor Toward $\mathbf{H g}^{2+}$}

\author{
Young-A Son ${ }^{\dagger}$ and Junemin Park \\ Department of Advanced Organic Materials and Textile System Engineering, \\ Chungnam National University, Daejeon, Korea
}

(Received: August 23, 2012 / Revised: September 12, 2012 / Accepted: September 22, 2012)

\begin{abstract}
Rhodamine dyes belong to xanthene family has excellent photostability and photophysical properties. In rhodamine dyes, Rhodamine 6G and its precursors also have xanthene chromophore and it shows high fluorescent quantum yield. Rhodamine 6G derivates are simple to synthesis and its high sensitivity and water solubility are suitable as good chemosensor. In this regard, Rhodamine $6 \mathrm{G}$ derivates which have selectivity to specific metal cation can used to detect various heavy metal ions. In this study, rhodamine $6 \mathrm{G}$ derivatives were synthesized by reaction of rhodamine $6 \mathrm{G}$ hydrazide and glyoxal and 4-phenyl thiosemicarbazide and it showed colorimetric and fluorescence sensing toward $\mathrm{Hg}^{2+}$ ion. This novel chemosensor was analyzed and measured on UV-Vis and fluorescence spectrophotometer. HOMO/LUMO values were also calculated by computational calculation.
\end{abstract}

Keywords: rhodamine $6 G$, chemosensor, absorbance, fluorescence, heavy metal ions, HOMO/LUMO

\section{Introduction}

In environment, mercury is the one of famous toxic heavy metal which could cause various diseases for living organisms. For this reason the many fluorescent chemosensor was studied for sensing mercury ${ }^{1,2)}$. Rhodamine was first synthesized by Noelting and Dziewonsky in 1905 and has been widely used in many research fields, including the lasing medium in dye lasers and fluorescent markers in biological studies ${ }^{3)}$. The rhodamine based dyes are functional substance to sense metals. So many previous reports, showing rhodamine derivatives are the high-quality to sense metal ions like $\mathrm{Hg}^{2+}, \mathrm{Cu}^{2+}, \mathrm{Fe}^{3+}, \mathrm{Zn}^{2+}, \mathrm{Pb}^{2+}, \mathrm{Pd}^{2+}, \mathrm{Cr}^{3+}$, $\mathrm{Ba}^{2+}$ etc. $^{4-6)}$.

Sensing principle of rhodamine, spirolactam or spirolactone derivatives are nonfluorescent and colorless, but ring-opening of the corresponding spirolactam /lactone gives rise to strong fluorescence emission.

In general, rhodamine derivative displays a red color change and strong fluorescence in acidic solutions by activation of a carbonyl group in a spirolactone or spirolactam moiety.

${ }^{\dagger}$ Corresponding author: Young-A Son (yason@cnu.ac.kr) Tel.: +82-42-821-6620 Fax.: +82-42-823-3736 (C)2012 KSDF 1229-0033/2012-09/158-164
In a similar way, an appropriate ligand on a spirolactam ring can induce a color change as well as a fluorescence change upon addition of metal ions ${ }^{7-9)}$.

In this study, we reported a novel class of chemosensor involved in rhodamine $6 \mathrm{G}$ based on 4-phenyl thiosemicarbazide. This chemosensor can detect $\mathrm{Hg}^{2+}$ ion, which release red fluorescence emission compared with other heavy metal ions like $\mathrm{Hg}^{2+}, \mathrm{Zn}^{2+}, \mathrm{Ag}^{2+}$, $\mathrm{Ba}^{2+}, \mathrm{Pb}^{2+}, \mathrm{Fe}^{3+}$. Its properties of $\mathrm{Hg}^{2+}$ detection were investigated and analyzed in details. Structural analysis of this novel chemosensor dye was identified by Proton -NMR, Mass. Its absorption and fluorescence emission measured by job's plot method.

Last, electron distribution and energy level calculation such as HOMO and LUMO was computationally simulated using $\mathrm{DMol}^{3}$ program of Material Studio 4.3 package.

\section{Experimental}

\subsection{Measurement}

All the reagents and solvents, used for synthesis of rhodamine $6 \mathrm{G}$ based dye sensor, were purchased from Aldrich and used without further purification.

Absorption and fluorescence spectra of the prepared 
dye sensor were measured with an Agilent 8453 spectrophotometer and a Shimadzu RF-5301PC fluorescent spectrophotometer, respectively. ${ }^{1} \mathrm{H}$ NMR spectra and elemental analyses were recorded AVANCE III 600 spectrometer operated at $600 \mathrm{MHz}$ NMR respectively. Mass spectra were recorded on a JEOL MStation [JMS -DX303].

HOMO/LUMO calculation and modeling simulation proceed with $\mathrm{DMol}^{3}$ of Material Studio 4.3.

\subsection{Synthesis}

Rhodamine 6G hydrazide (compound 1) was synthesized in a high yield from rhodamine 6G according to the literature procedure (compound 1$)^{10,11)}$.

Rhodamine 6G hydrazide reacted with glyoxal gives result as compound 2 according to the literature ${ }^{12)}$. 4-phenyl thiosemicarbazide $0.167 \mathrm{~g}(1 \mathrm{mmol})$ and compound $20.469 \mathrm{~g}$ (1 $\mathrm{mmol})$ were dissolved in $40 \mathrm{ml}$ of acetic acid and refluxed for $8 \mathrm{~h}$, then cooled to room temperature. The red precipitate was collected by filtration and washed with acetic acid and dried in vacuum(Scheme 1).

The solid was purified by chromatography on $\mathrm{SiO}_{2}$ eluted with $10 \%$ ethyl acetate in $\mathrm{CHCl}_{3}$ to give Chemosensor 1 as $0.208 \mathrm{~g}(37 \%)^{13,14)}$.

\section{Result and Discussion}

\subsection{Analysis data of chemosensor 1}

${ }^{1} \mathrm{H}-\mathrm{NMR}\left(600 \mathrm{MH}_{\mathrm{Z}}, \mathrm{DMSO}_{4}\right): 11.88(\mathrm{~s}, 1 \mathrm{H}), 10.041(\mathrm{~s}$, $1 \mathrm{H}), \quad 8.44-8.42(\mathrm{~d}, 2 \mathrm{H}), 7.88-7.87(\mathrm{~d}, 1 \mathrm{H}), 7.59-7.44(\mathrm{~m}$, $2 \mathrm{H}), 7.32-7.31(\mathrm{~d}, 1 \mathrm{H}), 7.29-7.16(\mathrm{~d}, 1 \mathrm{H}), 6.95-6.94(\mathrm{~d}$, $1 \mathrm{H}), 6.28-6.17(\mathrm{~d}, 4 \mathrm{H}), \quad 5.14-5.04(\mathrm{~m}, 3 \mathrm{H}), 3.18-3.02(\mathrm{~m}$ $4 \mathrm{H}), 2.07-1.83(\mathrm{~m}, 6 \mathrm{H}), 1.22-1.09(\mathrm{~m}, 6 \mathrm{H})$ (Figure 1). Anal. Calcd: for $\mathrm{C}_{35} \mathrm{H}_{35} \mathrm{~N}_{7} \mathrm{O}_{2} \mathrm{~S}: \mathrm{C}, 68.05 ; \mathrm{H}, 5.71 ; \mathrm{N}$, 15.87; Found : C, 71.67; H, 7.30; N, 9.47. MS m/z: $617.7(\mathrm{M}+)$. M.P : $202.6^{\circ} \mathrm{C}$.

\subsection{Sensing of $\mathrm{Hg}^{2+}$ in acetonitrile}

Photograph image for proving the characteristic of chemosensor 1 , showed chemosensor 1 has sensing ability toward $\mathrm{Hg}^{2+}$ ((a) in Figure 2).

And image which use fluorescence showed that chemosensor 1 has sensitivity toward $\mathrm{Hg}^{2+}$ than other metal ions ((b) in Figure 2).

Chemosensor 1 has nonfluorescent and colorless, but ring-opening of the corresponding spirolactam gives rise to strong fluorescence emission. This mechanism of these reactions, colorimetric and fluorescence, are followed by the literature reference ${ }^{7)}$.

\section{Rhodamine Hydrazine(Compound 1)}<smiles>CC/N=c1\cc2oc3cc(NCC)c(C)cc3c(-c3ccccc3C(=O)OCC)c-2cc1C</smiles><smiles></smiles>

\section{Compound 2}

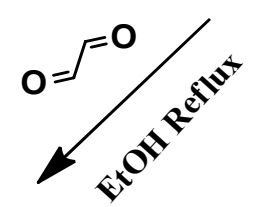<smiles>CCNc1cc2c(cc1C)C1(c3cc(C)c(NCC)cc3O2)c2ccccc2C(=O)N1/N=C/C=O</smiles><smiles>CCCCCCCCCCCNc1cc2c(cc1C)C1(O2)c2ccccc2C(=O)N(N=CC=N)c2cc(NCC)c(C)cc21</smiles>

Scheme 1. Synthesis of rhodamine 6G based new chemosensor (chemosensor 1). 


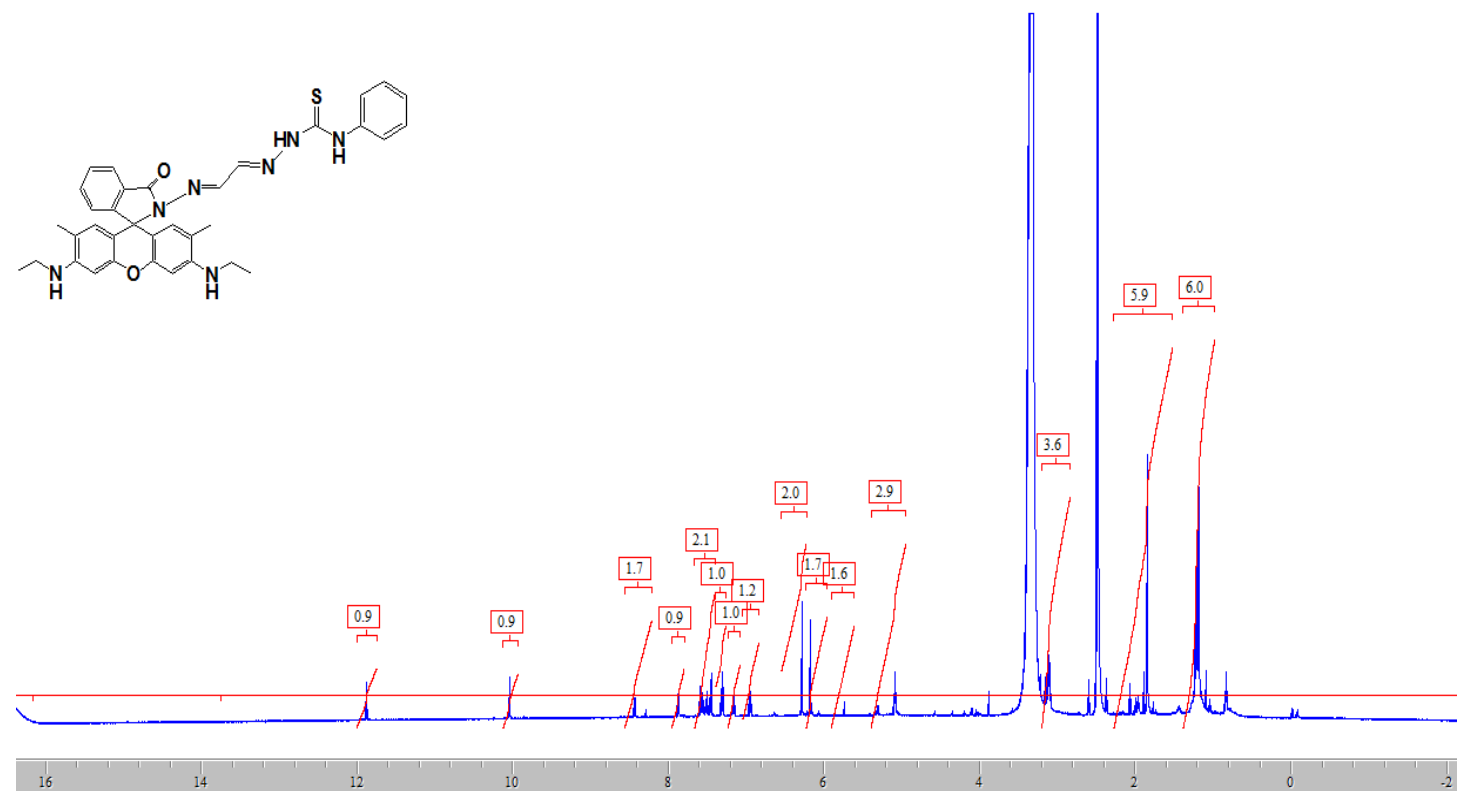

Figure 1. H-NMR data of Chemosensor 1.

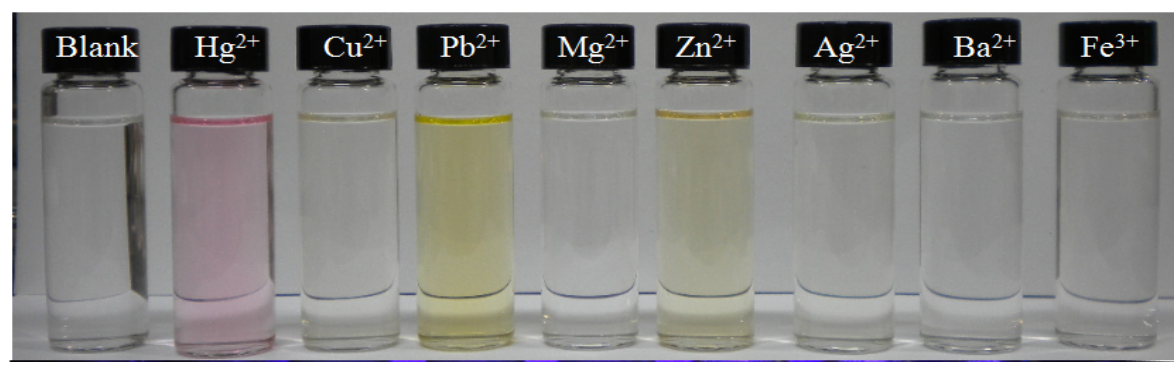

(a)

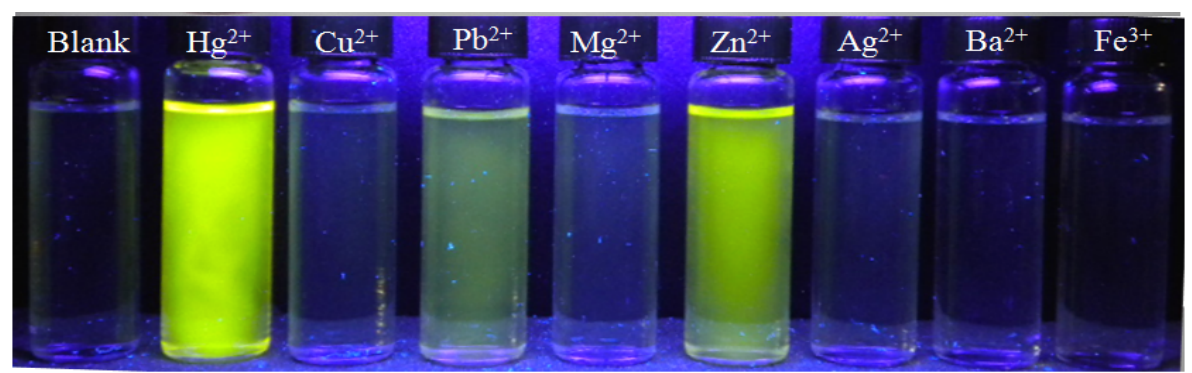

(b)

Figure 2. Photographs of absorption (a) and emission (b) sate for chemosensor 1.

(a) Various colorimetric absorption of chemosensor 1 and metal ions in acetonitrile.

(b) Various fluorescence emission of chemosensor 1 and metal ions in acetonitrile.

\subsection{UV Visible spectra and fluorescence of chemosensor 1}

To investigate the selectivity of chemosensor 1 with $\mathrm{Hg}^{2+}$ the absorption response between chemosensor 1 and $\mathrm{Hg}^{2+}\left(1 \times 10^{-5} \mathrm{~mol}\right)$ was monitored by UV-Visible absorption in acetonitrile as shown in Figure 3.

A strong absorption peak at $523 \mathrm{~nm}$ and color of chemosensor 1 was changed from colorless to red with $\mathrm{Hg}^{2+}$.

Besides in attendance observed be color changes between chemosensor 1 and $\mathrm{Zn}^{2+}$, between chemosensor 1 and $\mathrm{Pb}^{2+}$.

In addition, the fluorescence intensity of chemosensor 1 , the fluorescence peak appeared at $553 \mathrm{~nm}$ when mixed 


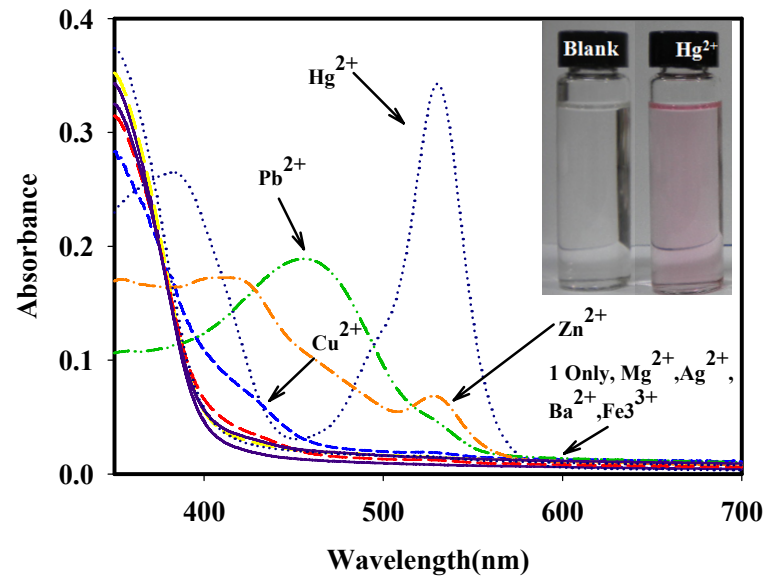

Figure 3. The absorption spectra of chemosensor $1(1 \mathrm{x}$ $\left.10^{-5} \mathrm{~mol}\right)$ when it mixed with various metal ions $\left(1 \times 10^{-5} \mathrm{~mol}\right)$ in acetonitrile. Inset: showing the change of color before and addition of $\mathrm{Hg}^{2+}$.

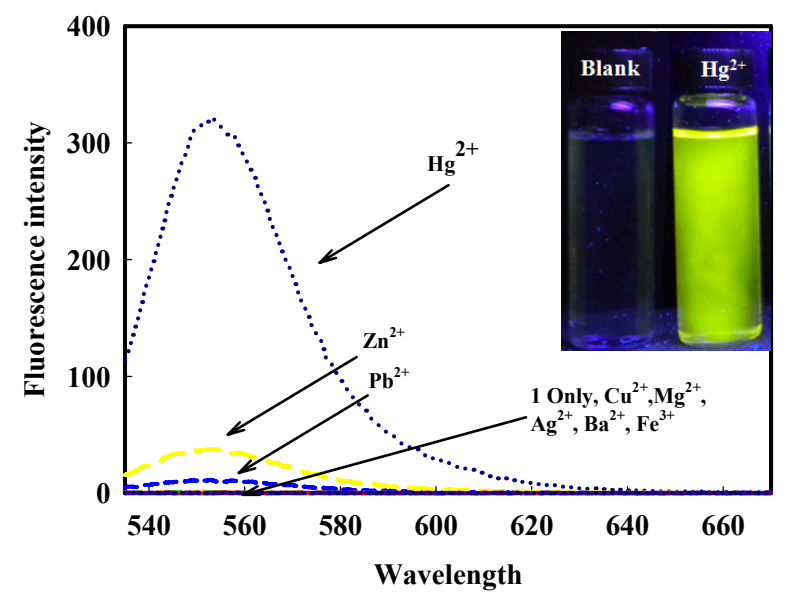

Figure 4. The fluorescence intensity of chemosensor 1 (1x $\left.10^{-5} \mathrm{~mol}\right)$ when it mixed with various metal ions $\left(1 \times 10^{-5} \mathrm{~mol}\right)$ in acetonitrile. Inset: showing the change of fluorescence color before and addition of $\mathrm{Hg}^{2+}$.

with $\mathrm{Hg}^{2+}$ (Figure 4). Although the fluorescences of $\mathrm{Zn}^{2+}$, $\mathrm{Pb}^{2+}$, were occurred at $553 \mathrm{~nm}$ when mixed with chemosensor 1 , the peaks are very weak fluorescence intensity compared with $\mathrm{Hg}^{2+}$.

\subsection{Metal competition of chemosensor 1}

Furthermore, to prove the selectivity of chemosensor 1, with other metal ion was added in mixture of chemosensor 1 and $\mathrm{Hg}^{2+}$. As shown in Figure 5 we can prove that $\mathrm{Cu}^{2+}, \mathrm{Fe}^{3+}$ have little disturb competition toward $\mathrm{Hg}^{2+}$. Although effect of $\mathrm{Cu}^{2+}, \mathrm{Fe}^{3+}$, it is confirmed that chemosensor 1 has selectivity toward $\mathrm{Hg}^{2+}$ when use fluorescence.

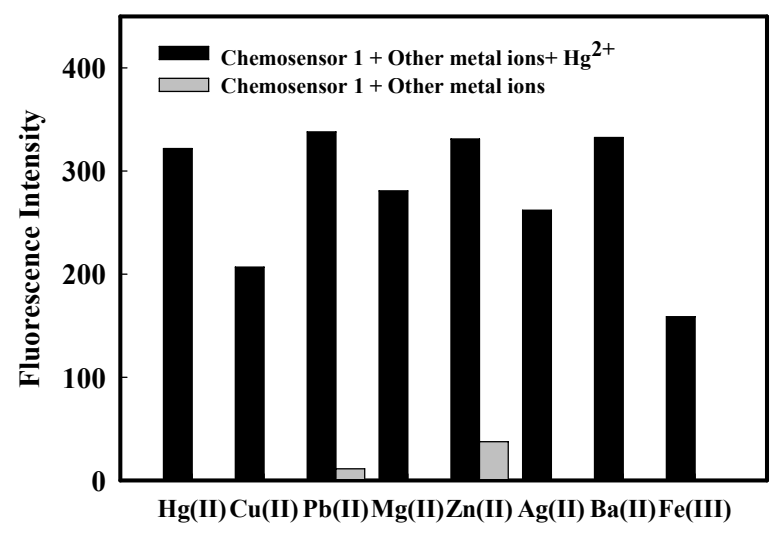

Figure 5. The fluorescence intensity of chemosensor $1(1 \mathrm{x}$ $\left.10^{-5} \mathrm{~mol}\right)$ with $\mathrm{Hg}^{2+}\left(1 \times 10^{-5} \mathrm{~mol}\right)$ when it complete with other metal ion $1 \times 10^{-5} \mathrm{~mol}$ ) in acetonitrile.

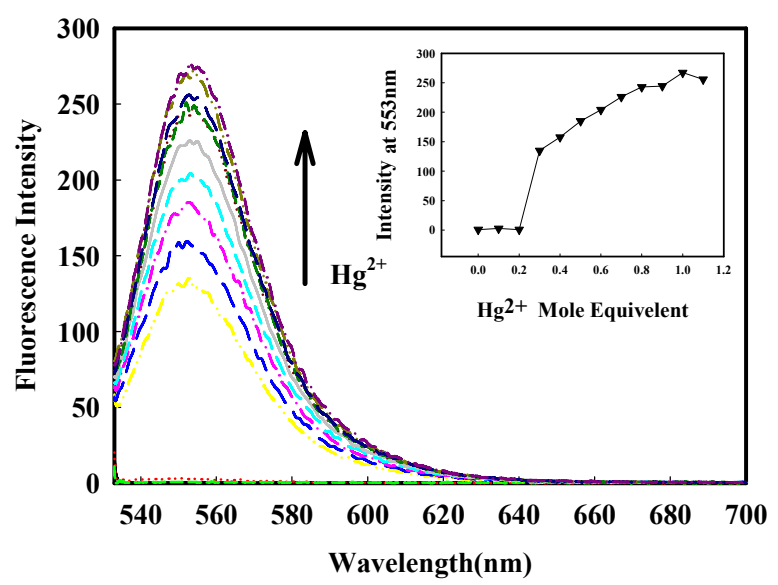

Figure 6. Fluorescence intensity changes of chemosensor 1 depend on the addition of $\mathrm{Hg}^{2+}$. Inset: showing fluorescence intensity addition of $\mathrm{Hg}^{2+}$ mole equivalent.

\subsection{UV Visible spectra and fluorescence intensity of $\mathrm{Hg}^{2+}$ titration}

To prove the interaction of chemosensor 1 and $\mathrm{Hg}^{2+}$, fluorescence titration of chemosensor 1 and $\mathrm{Hg}^{2+}$ was performed. When $\mathrm{Hg}^{2+}$ added, the fluorescence peak was enhanced at $553 \mathrm{~nm}$ (Figure 6). The fluorescence emission color was changed from colorless to greenish yellow with addition of $\mathrm{Hg}^{2+}$.

In addition UV-Visible titration of chemosensor 1 and $\mathrm{Hg}^{2+}$ was also proved for the interaction(Figure 7). UV-Visible absorbance peak pointed high intensity at $523 \mathrm{~nm}$.

The solution color was changed from colorless to red with addition of $\mathrm{Hg}^{2+}$ indicated by changes near $320 \mathrm{~nm}$ absorption peak intensity was decreased when 


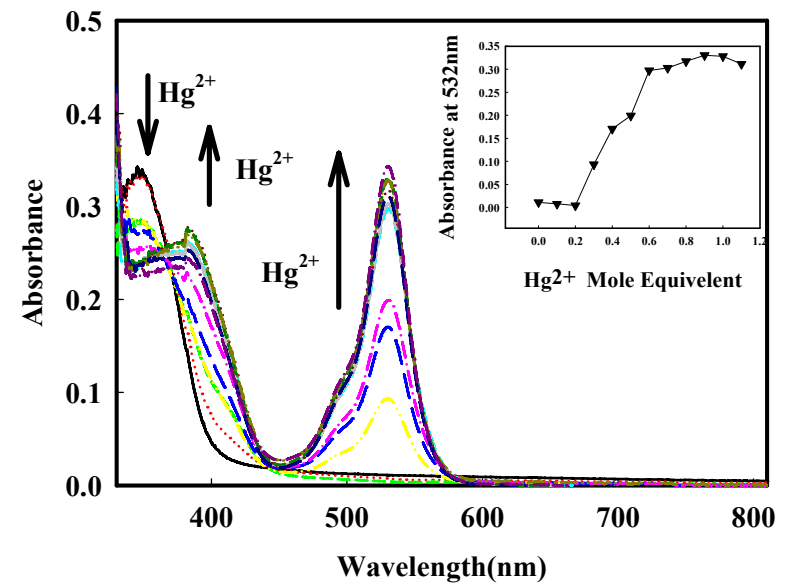

Figure 7. UV-vis absorbance changes of chemosensor 1 depend on the addition of $\mathrm{Hg}^{2+}$. Inset: showing UVVisible absorbance addition of $\mathrm{Hg}^{2+}$ mole equivalent.

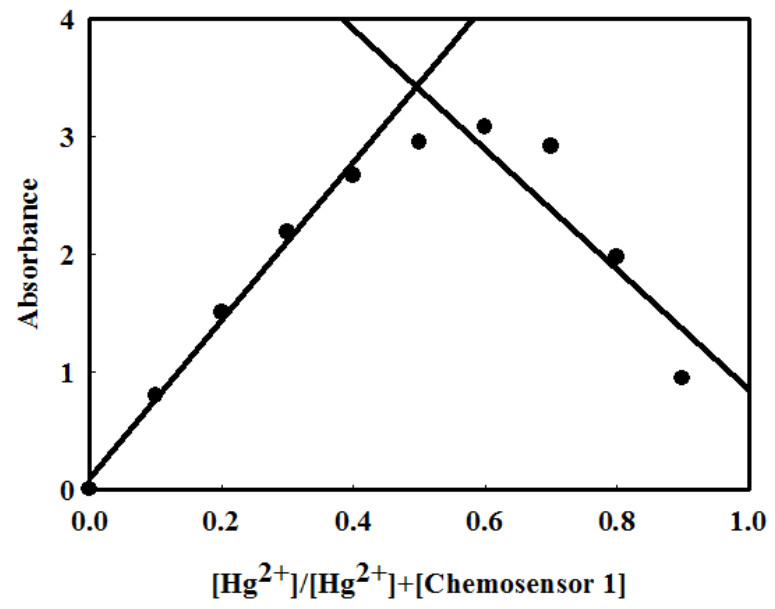

Figure 8. To use Job's plot, chemosensor 1 and $\mathrm{Hg}^{2+}$ ion mixture was monitored at $523 \mathrm{~nm}$ wavelength: the total concentration of $\left[\mathrm{Hg}^{2+}\right]+\lceil$ chemosensor 1$]$ was $5.0 \times 10^{-5} \mathrm{~mol}$.

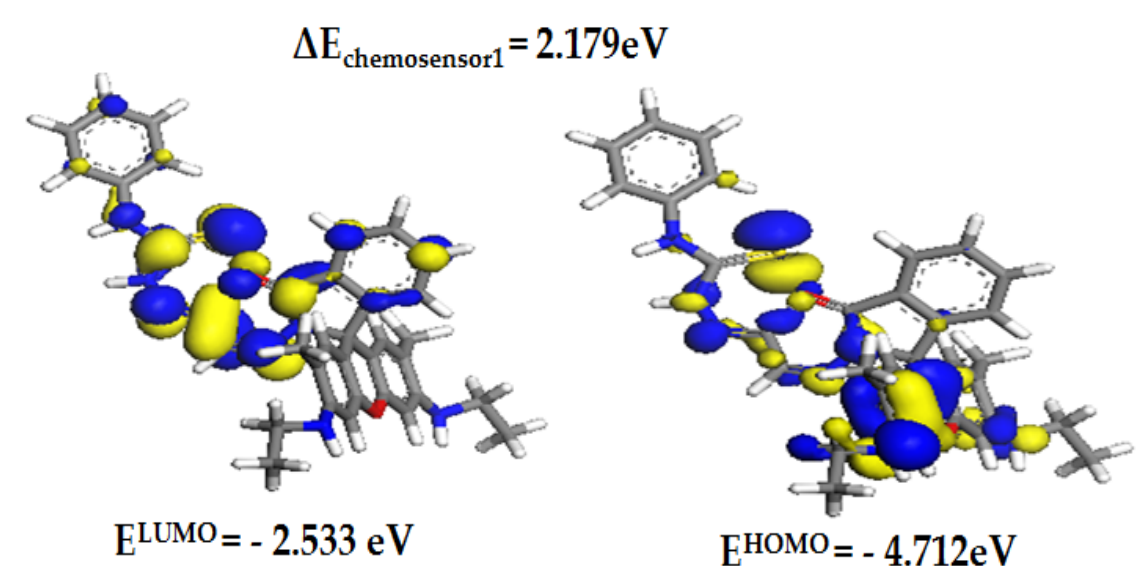

Figure 9. Electron distributions and HOMO/LUMO energy levels of chemosensor 1.

chemosensor 1 contain more $\mathrm{Hg}^{2+}$, and also another two peaks intensity increased at near $400 \mathrm{~nm}$ and $523 \mathrm{~nm}$ as shown in Figure 7.

\subsection{Jobs method of chemosensor 1 toward $\mathrm{Hg}^{2+}$}

We investigated the binding ratio between chemosensor 1 and $\mathrm{Hg}^{2+}$ using the Job's method ${ }^{15,16)}$.

For the measurement of Job's plot method, various molar ratios between chemosensor 1 and $\mathrm{Hg}^{2+}$ metal ions $(0: 10,1: 9,2: 8,3: 7,4: 6,5: 5,6: 4,7: 3,8: 2,9: 1)$ in $\mathrm{MeCN}$ were prepared. The relationship between maximum absorption peaks versus various mole fractions is shown in Figure 8.

The result take the 1:1 binding ratio of chemosensor 1 toward $\mathrm{Hg}^{2+}$ with total concentration of $\left[\mathrm{Hg}^{2+}\right]$ $+\left[\right.$ chemosensor 1] at $5.0 \times 10^{-5} \mathrm{~mol}$.
The absorbance made average lines from molar fraction of $\mathrm{Hg}^{2+} 0$ to 0.4 and from molar fraction of $\mathrm{Hg}^{2+} 0.5$ to 0.9 , two lines met at 0.5 molar fraction.

\subsection{Electron distributions of chemosensor 1}

We computationally calculated to investigate electron distributions and HOMO/LUMO energy levels of chemosensor 1. It has been simulated with Material Studio 4.3 program which is the quantum mechanical code using density functional theory.

Perdew-Burke-Ernzerhof (PBE) function of generalized gradient approximation (GGA) level with double numeric polarization basis set was used to calculate the energy level of the frontier molecular orbits ${ }^{17-19)}$. As shown in Figure 9, chemosensor 1 was calculated electron distirbutions and its HOMO/LUMO energy levels of chemo- 
sensor 1

HOMO and LUMO values were calculated respective $-4.712 \mathrm{eV}$ and $-2.533 \mathrm{eV}$. In this regard, the $\triangle \mathrm{E}$ value was finally calculated $-2.179 \mathrm{eV}$.

HOMO and LUMO states were showed that electron distributions moved from xanthene part to 4-phenyl thiosemicarbazide parts in structure of chemosensor 1 . This indicates that chemosensor 1 has interesting property of intra molecular charge transfer system.

\section{Conclusion}

In this study, we synthesized rhodamine $6 \mathrm{G}$ based dye which characteristic is proved by various metal ions $\left(\mathrm{Hg}^{2+}, \mathrm{Zn}^{2+}, \mathrm{Ag}^{2+}, \mathrm{Ba}^{2+}, \mathrm{Pb}^{2+}, \mathrm{Mg}^{2+}, \mathrm{Fe}^{3+}\right)$. It was proved by H-NMR, E.A, and Mass spectrum.

The result showed that chemosensor 1 changed from colorless to red color absorption and colorless to yellowish green color fluorescence intensity with $\mathrm{Hg}^{2+}$. This sensor's reaction ratio with $\mathrm{Hg}^{2+}$ revealed 1:1 from job's plot method. HOMO/LUMO energy potential was invested by $\mathrm{Dmol}^{3}$ program. In addition, chemosensor 1 also has interesting property of intra-molecular charge transfer (ICT) system.

\section{Acknowledgements}

This research was supported by the Basic Science Research Program through the National Research Foundation of Korea (NRF) funded by the Ministry of Education, Science and Technology (Grant no. 2011002 2326). This research was supported by a grant from the fundamental R\&D program for core technology of materials funded by the ministry of knowledge economy, Republic of Korea.

\section{References}

1. A. Guerri, F. Costela, A. Figuera, J. M. Florido, F. Sastre, and R. Sastre, Laser Action from Rhodamine 6G-doped Poly(2-hydroxyethyl methacrylate) Matrices with Different Crosslinking Degrees, Chem. Phys. Lett., 209(4), 352(1993).

2. S. B. O'Reilly, B. Lettmeier, R. M. Gothe, C. Beinhoff, U. Siebert, and G. Drasch, Mercury as a Serious Health Hazard for Children in Gold Mining
Areas, Environmental Research, 107(1), 89(2008).

3. N. E. Dziewonsky and K. B. Dtsch, Zur Kenntniss Der Rhodamine, Chem. Ges., 38(3), 3516(1905).

4. L. F. Zhang, J. L. Zhao, X. Zeng, L. Mu, X. K. Jiang, M. Deng, J. X. Zhang, and G. Wei, Tuning with $\mathrm{pH}$ : The Selectivity of a New Rhodamine B Derivative Chemosensor for $\mathrm{Fe}^{3+}$ and $\mathrm{Cu}^{2+}$, Sensors and Actuators B, 160(1), 662(2011).

5. K. P. Prathish, D. James, J. Jaisy, and T. P. Rao, Dual Optoelectronic Visual Detection and Quantification of Spectroscopically Silent Heavy Metal Toxins: A Multi-measurand Sensing Strategy Based on Rhodamine 6G as Chromo or Fluoro Ionophore, Analytica Chimica Acta, 647(1), 84(2009).

6. Y. Ma, X. T. Zhang, Z. S. Guan, Y. A. Cao, and J. N. Yao, Effects of Zinc(II) and Iron(III) Doping of Titania Films on Their Photoreactivity to Decompose Rhodamine B, Journal of Materials Research, 16(10), 2928(2001).

7. X. Chen, T. Pradhan, F. Wang, J. S. Kim, and J. Yoon, Fluorescent Chemosensors Based on Spiroring -Opening of Xanthenes and Related Derivatives, Chem. Rev., 112(3), 1910(2012).

8. Y. L. Kun, Y. Liu, Y. Han, and D. Xue, Interaction of Rhodamine B with BaMoO4 Nanoparticles in Different Reverse Micelles, Huaxue Xuebao, 63(1), 18(2005).

9. H. N. Kim, M. H. Lee, H. J. Kim, J. S. Kim, and J. Yoon, A New Trend in Rhodamine-Based Chemosesnors: Application of Spirolactam RingOpening to Sensing Ions, Chem. Soc. Rev., 37, 1465(2008).

10. Y. Xiang, A. Tong, P. Jin, and Y. Ju, New Fluorescent Rhodamine Hydrazone Chemosensor for $\mathrm{Cu}(\mathrm{II})$ with High Selectivity and Sensitivity, Org. Lett., 8(13), 2863(2006).

11. Z. Zhang, Y. Zheng, W. Hang, X. Yan, and Y. Zhao, Sensitive and Selective Off-on Rhodamine Hydrazide Fluorescent Chemosensor for Hypochlorous Acid Detection and Bioimaging, Talanta, 85(1), $779(2011)$.

12. H. Li, J. Fan, F. Song, H. Zhu, J. Du, S. Sun, and X. Peng, Fluorescent Probes for $\mathrm{Pd}^{2+}$ Detection 
by Allylidene-Hydrazone Ligands with Excellent Selectivity and Large Fluorescence Enhancement, Chem. Eur. J., 16(41), 12349(2010).

13. T. Kim, K. Jang and S. Jeon, Synthesis of Red Disperse Dyes with Various Diazo Components and Coloration of Unmodified Pure Polypropylene Fibers, Textile Coloration and Finishing(J. Korean Soc. Dyers \& Finishers), 22(1), 1(2010).

14. E. M. Lee, S. Y. Gwon, B. C. Ji, and S. H. Kim, Thermo- and Acid/Base-induced Spectral Switching of a Poly(N-isopropylacrylamide) Copolymer Containing Benzopyran-based D- $\pi$-A type Dye Units, Textile Coloration and Finishing(J. Korean Soc. Dyers \& Finishers), 22(3), 181(2010).

15. J. Wang and X. Qian, A Series of Polyamide Receptor
Based PET Fluorescent Sensor Molecules: Positively Cooperative $\mathrm{Hg}^{2+}$ Ion Binding with High Sensitivity, Org. Lett., 8(17), 3721(2006).

16. P. M. Carthy, Simplified Experimental Route for Obtaining Job's Curve, Analytical Chemistry, 50(14), 2165(1978).

17. B. Delley, An All-Electron Numerical Method for Solving The Local Density Functional for Polyatomic Molecules, J. Chem. Phys., 92(1), 508(1990).

18. B. Delley, From Molecules to Solids with the $\mathrm{DMol}^{3}$ Approach, J. Chem. Phys., 113(18), 7756(2000).

19. A. D. Boese and N. C. Handy, A New Parametrization of Exchange-Correlation Generalized Gradient Approximation Functionals, J. Chem. Phys., 114(13), 5497(2001). 